\title{
ENSINO FUNDAMENTAL DE NOVE ANOS: PRINCIPAIS ORIENTAÇÕES LEGAIS E ADMINISTRATIVAS
}

\author{
Cristiane Batistioli Vendrame \\ Maria Angélica Olivo Francisco Lucas \\ Universidade Estadual de Maringá - UEM
}

\section{RESUMO}

O objetivo deste artigo é apresentar as principais orientações legais e administrativas para a implantação do ensino fundamental de nove anos presentes nos documentos oficiais elaborados e difundidos pelo MEC. Trata-se de uma pesquisa bibliográfica acompanhada de análise documental, transitando entre elementos oriundos das políticas públicas educacionais, da história da educação brasileira e reflexões acerca da organização do ensino. O estudo da legislação e da história da educação brasileira, ao longo das últimas cinco décadas, indica que houve, progressivamente, ampliação da escolarização obrigatória, sinalizando para um ensino fundamental com nove anos de duração, com início aos seis anos de idade, como efetivado em 2005 e 2006, respectivamente pelas leis $n^{\circ} 11.114$ e 11.274. Reconhecemos que esforços foram realizados pelo MEC no sentido de orientar tal ampliação. Todavia, não foram suficientes para garantir êxito em termos de organização do ensino, ampliando as possibilidades de aprendizagem das crianças. Isto significa que as políticas públicas educacionais precisam ser pensadas e elaboradas, considerando tanto sua dimensão econômica e de gestão, como, pedagógica, tendo em vista a elevação da qualidade da educação brasileira.

Palavras-chave: Ensino fundamental de nove anos; orientações legais e administrativas; políticas públicas; organização do ensino.

\section{ELEMENTARY SCHOOL OF NINE YEARS: KEY LEGAL AND ADMINISTRATIVE GUIDELINES}

\begin{abstract}
The purpose of this article is to present the main legal and administrative guidelines for the implementation of the elementary school with nine years present in official documents elaborated and disseminated by MEC. It is a literature research followed by documentary analysis, shifting between elements coming from the public educational policies, the history of Brazilian education and reflections about the organization of the education. The study of law and the history of Brazilian education, over the last five decades, indicates to a progressively increase of the mandatory schooling, pointing for a primary school with nine years of duration, starting at six years of age, as effected in 2005 and 2006,respectively by the laws $\mathrm{n}^{\circ} 11.114$ e 11.274. We recognize that efforts were done by the MEC in the sense of guiding such expansion. However, they weren't sufficient guarantee successes in terms of organization of teaching, expanding the children learning opportunities. This means that the educational public policies need to be conceived and developed, considering both its economic size and management as teaching, in order to improve the quality of brazilian education.

Keywords: elementary school with nine years; legal and administrative guidelines; public policies; teaching organization.
\end{abstract}




\title{
Introdução
}

O objetivo deste artigo é apresentar as principais orientações legais e administrativas para a implantação do ensino fundamental de nove anos presentes nos documentos oficiais elaborados e difundidos pelo MEC. As reflexões aqui apresentadas fazem parte de um estudo maior que visou investigar como tais documentos tratam as contribuições da Teoria Histórico-Cultural (THC), em especial as oriundas da obra luriana, para a compreensão do processo de apropriação da escrita (VENDRAME, 2015).

Trata-se de uma pesquisa bibliográfica com análise documental, estudo que transitou entre políticas públicas para a educação, reflexões acerca da organização do ensino tendo em vista o processo de aprendizagem da linguagem escrita e elementos oriundos da história da educação.

Cabe ainda destacar que a ampliação do tempo de escolarização obrigatória é um movimento mundial e, mesmo na América do Sul, são vários os países cuja escolarização obrigatória tem nove anos de duração ou mais. É o caso do Paraguai - 9 anos, Argentina e Uruguai - 10 anos, Colômbia e Peru - 11 anos, Venezuela - 12 anos (SCHNEIDER; DURLI, 2009). Contudo,

\begin{abstract}
A ampliação do ensino fundamental para nove anos no Brasil se coaduna à prática de vários países que apresentam em média 12 anos de escolarização básica, incluindo países da América Latina. Assim, o Brasil busca alinhar-se a tal situação, na expectativa de melhorar a educação no país, pois historicamente a educação brasileira enfrenta desafios ainda não superados: altas taxas de evasão e repetência; analfabetismo; problemas na formação, carreira e valorização de professores; infraestrutura inadequada e, a contradição entre acesso e sucesso escolar, já que, o ingresso nas escolas brasileiras não tem representado a apropriação do processo de alfabetização, sendo este um dos maiores impasses a tão buscada qualidade na educação (FURGHESTTI; GRECO; CARDOSO, 2012, p. 2).
\end{abstract}

Ao longo da história da educação brasileira houve movimentos de ampliação do tempo de duração do ensino obrigatório, explicitados nas Leis de Diretrizes e Bases da Educação de 1961, 1971 e 1996. Segundo a LDB n. ${ }^{\circ}$ 4.024/61, o ensino era obrigatório e deveria ser ministrado em quatro séries anuais, podendo estender sua duração até seis anos, conforme orientava o Plano Nacional de Educação de 1962, e a criança podia ingressar na escola a partir dos sete anos de idade. Para a LDB n. ${ }^{\circ} 5.692 / 71$, o $1^{\circ}$ grau tinha a duração de oito anos, era também obrigatório e estendia-se dos sete (idade mínima para ingressar) aos quatorze anos de idade. Já pela LDB n. ${ }^{\circ}$ 9.394, quando de sua promulgação, em 1996, o ensino fundamental, obrigatório e gratuito, deveria ter a duração mínima de oito anos, iniciando-se aos sete anos de idade, objetivando a formação básica do cidadão, por meio do desenvolvimento pleno da leitura, da escrita e do cálculo. Vale destacar que a expressão "mínima" abriu, desde então, a possibilidade de ampliação do tempo de duração desse nível de ensino. Além disso, tal lei também previa progressiva extensão da obrigatoriedade e gratuidade ao ensino médio (o qual passou a ser obrigatório a partir de 2009, com a aprovação da Lei 12.061).

Uma etapa do processo de ampliação do ensino obrigatório no Brasil efetivou-se por meio de duas leis que alteram a atual LDB. A primeira, Lei $\mathrm{n}^{\circ} 11.114$ (2005), entre outras modificações, afirma que é dever dos pais ou responsáveis matricular as crianças, a partir dos seis anos de idade no ensino fundamental. A segunda, Lei $n^{\circ} 11.274$ (2006), determina 
que o ensino fundamental tenha a duração de nove anos, com matrícula obrigatória a partir dos seis anos de idade.

Na realidade, essa ampliação já estava anunciada na meta 2 do ensino fundamental do Plano Nacional de Educação (PNE), Lei n. ${ }^{\circ} 10.172$ (2001), o qual indicava a intenção de incluir, progressivamente, a criança de seis anos de idade, anteriormente matriculada na educação infantil, nesse nível de ensino. Com isso, pretendia-se "[...] oferecer maiores oportunidades de aprendizagem no período da escolarização obrigatória e assegurar que, ingressando mais cedo no sistema de ensino, as crianças prossigam nos estudos, alcançando maior nível de escolaridade" (BRASIL, 2004a, p. 14).

Além das Leis de Diretrizes e Bases da Educação (Lei n. ${ }^{\circ} 4.024 / 61$, n. ${ }^{\circ} 5.692 / 71$ e n. ${ }^{\circ}$ 9394/96), há outros documentos oficiais que tratam do tempo de duração da escolarização obrigatória, como se pode verificar no quadro a seguir.

\begin{tabular}{|c|c|}
\hline LEI/ ANO & TEXTO DA LEI \\
\hline Lei no $4.024 / 61$ & $\begin{array}{l}\text { Art. } 26 \text { - O ensino primário será ministrado, no mínimo, em quatro séries } \\
\text { anuais. } \\
\text { Art. } 27 \text { - O ensino primário é obrigatório a partir dos sete anos e só será } \\
\text { ministrado na língua nacional. }\end{array}$ \\
\hline Acordo 1970 & $\begin{array}{l}\text { Os países que assinaram o Acordo de Punta del Este e Santiago assumiram } \\
\text { o compromisso de estabelecer } 6 \text { anos de duração para o Ensino } \\
\text { Fundamental. }\end{array}$ \\
\hline Lei n ${ }^{\circ} 5.692 / 71$ & $\begin{array}{l}\text { Art. } 18-\mathrm{O} \text { ensino de } 1^{\circ} \text { grau terá a duração de oito anos letivos e } \\
\text { compreenderá, anualmente, pelo menos, } 720 \text { horas de atividades. }\end{array}$ \\
\hline $\begin{array}{l}\text { Constituição } \\
\text { Federal/88 }\end{array}$ & $\begin{array}{l}\text { Art. } 208 \text { - O dever do Estado com a educação será efetivado mediante a } \\
\text { garantia de: } \\
\text { I - educação básica obrigatória e gratuita dos } 4 \text { (quatro) aos } 17 \text { (dezessete) } \\
\text { anos de idade, assegurada, inclusive, sua oferta gratuita para todos os que } \\
\text { a ela não tiveram acesso na idade própria. }\end{array}$ \\
\hline Lei ${ }^{\circ}$ 9.394/96 & $\begin{array}{l}\text { Art. } 32 \text { - O ensino fundamental, com duração mínima de oito anos, } \\
\text { obrigatório e gratuito na escola pública, terá por objetivo a formação } \\
\text { básica do cidadão. }\end{array}$ \\
\hline Lei $\mathrm{n}^{\circ} 10.172 / 01$ & $\begin{array}{l}\text { Art. } 1 \text { - Fica aprovado o Plano Nacional de Educação, constante do } \\
\text { documento anexo, com duração de dez anos. } \\
\text { Meta } 2 \text { - Ampliar para nove anos a duração do ensino fundamental } \\
\text { obrigatório com início aos seis anos de idade, à medida que for sendo } \\
\text { universalizado o atendimento na faixa de } 7 \text { a } 14 \text { anos. }\end{array}$ \\
\hline Lei $n^{\circ} 11.114 / 05$ & $\begin{array}{l}\text { O artigo } 1 \text { - dessa lei altera vários artigos da atual LDB, entre eles, o artigo } \\
\text { 6, que passa a vigorar com a seguinte redação: } \\
\text { Art. } 6 \text { - É dever dos pais ou responsáveis efetuar a matrícula dos menores, } \\
\text { a partir dos seis anos de idade, no ensino fundamental. }\end{array}$ \\
\hline Lei $n^{\circ} 11.274 / 06$ & $\begin{array}{l}\text { O artigo } 3 \text { - dessa lei altera o artigo } 32 \text { da atual LDB, que passa a vigorar } \\
\text { com a seguinte redação: } \\
\text { Art. } 32 \text { - O ensino fundamental obrigatório, com duração de nove anos, } \\
\text { gratuito, na escola pública, iniciando-se aos seis anos de idade, terá por } \\
\text { objetivo a formação básica do cidadão. } \\
\text { Art. } 5 \text { - Os Municípios, os Estados e o Distrito Federal terão prazo até } \\
2010 \text { para implementar a obrigatoriedade para o ensino fundamental. }\end{array}$ \\
\hline
\end{tabular}

Quadro 1: Documentos legais que apontam alterações no tempo de duração da escolarização obrigatória Fonte: Czyzewski (2012, p. 24). 
Partindo-se das informações do quadro acima, é possível identificar que a legislação educacional brasileira, ao longo das últimas cinco décadas, realizou progressivamente a ampliação da escolarização obrigatória e sinalizou para um ensino fundamental com nove anos de duração, com início aos seis anos de idade, como efetivado em 2005 e 2006, respectivamente pelas leis $\mathrm{n}^{\mathrm{o}} 11.114$ e 11.274. Poderíamos, ainda, acrescentar a este quadro a Emenda Constitucional 59, promulgada em novembro de 2009, por meio altera-se a redação dos incisos I e VII do artigo 208 da Constituição Federal. A partir dela a Educação Básica obrigatória e gratuita inicia-se aos quatro anos de idade, estendendo-se até aos dezessete e assegurando, inclusive, sua oferta gratuita para os que a ela não tiveram acesso na idade própria.

Tendo como objetivo acompanhar os sistemas de ensino na implantação do ensino fundamental de nove anos, o Ministério da Educação (MEC), por meio da Secretaria de Educação Básica (SEB), do Departamento de Políticas de Educação Infantil e Ensino Fundamental (DPE) e da Coordenação Geral do Ensino Fundamental (COEF), elaborou documentos orientadores que visam a esclarecer aspectos legais e a organização da escola em termos administrativos e pedagógicos. Alguns desses documentos trazem, exclusivamente, orientações legais e administrativas, com exceção do primeiro, no qual há apenas quatro páginas com orientações para a organização do trabalho pedagógico. Do total, apenas dois estão voltados para a reorganização da prática pedagógica necessária diante da reformulação do ensino fundamental, como podemos conferir no Quadro 2.

\begin{tabular}{|c|c|c|c|}
\hline ANO & DOCUMENTO & ORIENTAÇÃO & OBJETIVO \\
\hline 2004 & $\begin{array}{l}\text { Ensino Fundamental de Nove } \\
\text { anos: orientações gerais }\end{array}$ & $\begin{array}{l}\text { Administrativa e } \\
\text { Pedagógica }\end{array}$ & $\begin{array}{l}\text { Apresentar orientações gerais, no que } \\
\text { concerne ao estabelecimento de políticas } \\
\text { indutoras de modificações significativas } \\
\text { na estrutura da escola. }\end{array}$ \\
\hline 2004 & $\begin{array}{c}\text { Ensino Fundamental de Nove } \\
\text { Anos } 1^{\circ} \text { Relatório }\end{array}$ & Administrativa & $\begin{array}{l}\text { Apresentar as principais ações realizadas } \\
\text { pelo SEB/DPE/COEF até julho de } 2004 \\
\text { em parceria com as secretarias estaduais e } \\
\text { municipais de educação sobre os avanços } \\
\text { alcançados. }\end{array}$ \\
\hline 2005 & $\begin{array}{c}\text { Ensino Fundamental de Nove } \\
\text { Anos } 2^{\circ} \text { Relatório }\end{array}$ & Administrativa & $\begin{array}{l}\text { Apresentar as ações realizadas pelo } \\
\text { SEB/DPE/COEF juntamente com as } \\
\text { secretarias estaduais e municipais de } \\
\text { educação. }\end{array}$ \\
\hline 2006 & $\begin{array}{l}\text { Ampliação do Ensino } \\
\text { Fundamental para nove anos: } 3^{\circ} \\
\text { relatório do programa }\end{array}$ & Administrativa & $\begin{array}{l}\text { Atualizar as informações sobre } \mathrm{o} \\
\text { programa, responder a dúvidas e a } \\
\text { questionamentos dos sistemas de ensino. }\end{array}$ \\
\hline 2007 & $\begin{array}{l}\text { Ensino Fundamental de nove } \\
\text { anos: orientações para a } \\
\text { inclusão da criança de seis anos } \\
\text { de idade }\end{array}$ & Pedagógica & $\begin{array}{l}\text { Veicular orientações pedagógicas que } \\
\text { apontam o respeito às crianças como } \\
\text { sujeitos da aprendizagem. }\end{array}$ \\
\hline 2009 & $\begin{array}{l}\text { Ensino Fundamental de nove } \\
\text { anos: passo a passo do processo } \\
\text { de implantação }\end{array}$ & Administrativa & $\begin{array}{l}\text { Subsidiar gestores municipais e estaduais, } \\
\text { conselhos de educação, comunidade } \\
\text { escolar e demais órgãos e instituições no } \\
\text { processo de implantação do Ensino } \\
\text { Fundamental de nove anos. }\end{array}$ \\
\hline 2009 & $\begin{array}{l}\text { A criança de } 6 \text { anos, a } \\
\text { linguagem escrita e o Ensino } \\
\text { Fundamental de nove anos }\end{array}$ & Pedagógica & $\begin{array}{l}\text { Veicular orientações pedagógicas, tendo } \\
\text { em vista o trabalho com a linguagem } \\
\text { escrita em turmas com crianças de seis } \\
\text { anos de idade. }\end{array}$ \\
\hline
\end{tabular}

Quadro 2: Documentos oficiais elaborados para a implantação do Ensino Fundamental de nove anos Fonte: Vendrame (2014). 
Com base nos dados do quadro acima, reservamos para apresentar neste artigo, de forma detalhada, as principais orientações de cunho legal e administrativo elaboradas pelo MEC acerca da implantação do ensino fundamental de nove anos. Contudo, admitimos a impossibilidade de isolar tais aspectos do caráter didático-pedagógico que uma mudança dessa envergadura requer.

Serão foco de nossa análise os documentos apresentados na seguinte ordem:

- Ensino Fundamental de Nove anos: Orientações Gerais (BRASIL, 2004a);

- Ensino Fundamental de Nove Anos: $1^{\circ}$ Relatório do Programa (BRASIL, 2004b);

- Ensino Fundamental de Nove Anos: $2^{\circ}$ Relatório do Programa (BRASIL, 2005);

- Ampliação do Ensino Fundamental para nove anos: $3^{\circ}$ Relatório do Programa (BRASIL, 2006);

- Ensino Fundamental de nove anos: passo a passo do processo de implantação (BRASIL, 2009).

Por fim, reconhecemos que esforços foram realizados pelo MEC no sentido de orientar a implantação do ensino fundamental de nove, principalmente em termos legais e administrativos. Todavia, esses esforços não foram suficientes para garantir que tal ampliação fosse exitosa em termos de organização do ensino, ampliando as possibilidades de aprendizagem das crianças. Isto significa que as políticas públicas educacionais precisam ser pensadas e elaboradas, considerando suas dimensões econômica e de gestão, mas, principalmente, pedagógica, tendo em vista a elevação da qualidade da educação brasileira

\section{Implantação do Ensino Fundamental de nove anos: aspectos legais e administrativos}

Como já previsto em leis mencionadas anteriormente, o ensino fundamental de nove anos vinha sendo discutido pela SEB e pelos sistemas de ensino desde 2003. Buscando acompanhar os debates, dúvidas e questionamentos quanto à ampliação desse nível de ensino, o MEC publicou três relatórios - um em julho de 2004, outro em 2005 e o último em maio de 2006 -, todos frutos da realização de eventos regionais e nacionais.

O primeiro, intitulado "Ensino Fundamental de Nove Anos: $1^{\circ}$ Relatório do Programa" (BRASIL, 2004b), apresenta as principais ações implementadas até então pela SEB/DPE/COEF em parceria com as secretarias estaduais e municipais de educação e os avanços alcançados, a partir da realização de sete encontros regionais, em fevereiro de 2004, nas cidades de: Belo Horizonte, MG; Campinas, SP; Florianópolis, SC; São Luís, MA; Recife, PE; Rio Branco, AC; Goiânia, GO. Esses encontros também previam a produção de um boletim contendo relato de experiências, a realização de visitas técnicas e de um evento em nível nacional ao final daquele ano (BRASIL, 2004b).

Participaram dos encontros regionais representantes da União dos Dirigentes Municipais de Educação (Undime) e do Conselho Nacional de Educação (CNE), secretários estaduais e municipais de educação, equipes técnicas das secretarias de educação, diretores de escola, professores da educação infantil e do ensino fundamental, supervisores e inspetores de ensino, orientadores pedagógicos, entre outros profissionais da educação.

Tais encontros tinham como objetivo discutir, juntamente com estados e municípios, como implementar tais mudanças. Apesar de muitas secretarias apresentarem interesse em ampliar a duração do ensino fundamental para nove anos, menciona o documento, essas instâncias aguardavam definições a respeito de recursos financeiros e também de outros aspectos para tomar a decisão. Mesmo com dificuldades, cinco estados e 284 municípios escolheram por implantar o programa em 2003 e já tinham dados a serem analisados e discutidos com os demais por meio desses encontros regionais, que foram muito importantes 
por oferecerem ao MEC elementos para a elaboração de outros documentos, bem como sugestões de como continuar acompanhando e avaliando os programas de ampliação do ensino fundamental (BRASIL, 2004b).

Nesse relatório há a defesa de que

A ampliação em mais um ano de estudo deve produzir um salto na qualidade da educação: inclusão de todas as crianças de seis anos, menor vulnerabilidade a situações de risco, permanência na escola, sucesso no aprendizado e aumento da escolaridade dos alunos. (BRASIL, 2004b, p. $1)$.

O resultado desses encontros e o registro das discussões realizadas por meio do primeiro relatório foram essenciais para a elaboração do documento "Ensino Fundamental de Nove Anos - Orientações Gerais" que apresenta indagações por meio das quais as escolas são convidadas a pensar em outra perspectiva de currículo e escola, de modo a provocar mudanças no tradicional modelo curricular predominante em nosso ensino:

[...] imprescindível debater com a sociedade um outro conceito de currículo e escola, com novos parâmetros de qualidade. Uma escola que seja um espaço e um tempo de aprendizados de socialização, de vivências culturais, de investimento na autonomia, de desafios, de prazer e de alegria, enfim, do desenvolvimento do ser humano em todas as suas dimensões (BRASIL, 2004a, p. 11).

Com essas orientações o MEC visa estabelecer políticas que instiguem modificações expressivas na estrutura da escola, na reorganização dos tempos, dos espaços escolares, das formas de ensinar, de aprender, de avaliar, sugerindo a propagação de novas visões de currículo, conhecimento, aprendizado e desenvolvimento humano.

No referido documento, encontram-se discussões sobre a função educativa da instituição escolar, ou seja, sobre o papel da escola como polo gerador e irradiador de conhecimento e cultura. Aborda também a respeito do desenvolvimento do aluno, considerado a principal referência para a organização do tempo e do espaço da escola. Para tanto, a educação precisa ter como foco algumas características:

- O ser humano é ser de múltiplas dimensões;

- Todos aprendem em tempos e em ritmos diferentes;

- O desenvolvimento humano é um processo contínuo;

- O conhecimento deve ser construído e reconstruído, processualmente e continuamente;

- O conhecimento deve ser abordado em uma perspectiva de totalidade (BRASIL, 2004a, p. 13).

Respaldado pelo artigo 32 da atual LDB, tal documento ainda faz menção aos objetivos do ensino fundamental quanto à formação do cidadão:

I - o desenvolvimento da capacidade de aprender, tendo como meios básicos o pleno domínio da leitura, da escrita e do cálculo;

II - a compreensão do ambiente natural e social, do sistema político, da tecnologia, das artes e dos valores em que se fundamenta a sociedade; 
III - o desenvolvimento da capacidade de aprendizagem, tendo em vista a aquisição de conhecimentos e habilidades e a formação de atitudes e valores;

IV - o fortalecimento dos vínculos de família, dos laços de solidariedade humana e de tolerância recíproca em que se assenta a vida social (BRASIL, 2004a, p. 15).

O documento também recupera elementos das Diretrizes Curriculares Nacionais para a Educação Infantil (BRASIL, 2010), considerando-as como subsídio para a revisão da proposta pedagógica do novo ensino fundamental, o qual passa a receber crianças com seis anos de idade, reforçando, assim, a necessidade de articular essas duas esferas do ensino. Estabelece que:

- As propostas pedagógicas [...] devem promover em suas práticas de educação e cuidados a integração entre os aspectos físicos, emocionais, afetivos, cognitivo-linguísticos e sociais da criança, entendendo que ela é um ser total, completo e indivisível. Dessa forma, sentir, brincar, expressar-se, relacionar-se, mover-se, organizar-se, cuidar-se, agir e responsabilizar-se são partes do todo de cada indivíduo.

- Ao reconhecer as crianças como seres íntegros que aprendem a ser e a conviver consigo mesmas, com os demais e com o meio ambiente de maneira articulada e gradual, as propostas pedagógicas [...] devem buscar a interação entre as diversas áreas de conhecimento e aspectos da vida cidadã como conteúdos básicos para a constituição de conhecimentos e valores.

- Tudo isso deve acontecer num contexto em que cuidados e educação se realizem de modo prazeroso, lúdico.

- $[\ldots]$ as estratégias pedagógicas devem evitar a monotonia, o exagero de atividades 'acadêmicas' ou de disciplinamento estéril.

- As múltiplas formas de diálogo e interação são o eixo de todo o trabalho pedagógico.

- A participação dos educadores é mesmo participação e não condução absoluta de todas as atividades e centralização dessas em sua pessoa. Por isso, desde a organização do espaço, móveis, acesso a brinquedos e materiais, aos locais como banheiros, cantinas e pátios, até a divisão do tempo e do calendário anual de atividades, passando pelas relações e ações conjuntas com as famílias e os responsáveis, o papel dos educadores é legitimar os compromissos assumidos por meio das propostas pedagógicas (BRASIL, 2004a, p. 15-16)

Esses elementos reforçam que não se trata de repassar para as crianças de seis anos os conteúdos e as atividades da antiga primeira série, mas de elaborar uma nova estrutura de organização dos conteúdos em um ensino fundamental de nove anos de duração, ponderando o perfil dos alunos que agora iniciam esse nível de ensino. Destarte, ao professor cabe repensá-lo em seu conjunto, ocasião que pede uma nova práxis que aborde os saberes e os tempos, os métodos de trabalho e as reflexões na busca por uma escola de qualidade.

Para garantir uma nomenclatura comum às muitas possibilidades de organização desse nível de ensino (séries, ciclos, outros - conforme art. 23 da atual LDB), indica que as etapas do ensino fundamental assim nominadas: 


\begin{tabular}{|c|c|c|c|c|c|c|c|c|}
\hline \multicolumn{9}{|c|}{ Ensino Fundamental } \\
\hline \multicolumn{5}{|c|}{ Anos iniciais } & \multicolumn{4}{|c|}{ Anos finais } \\
\hline $1^{\circ}$ ano & $2^{\circ}$ ano & $3^{\circ}$ ano & $4^{\circ}$ ano & $5^{\circ}$ ano & $6^{\circ}$ ano & $7^{\circ}$ ano & $8^{\circ}$ ano & $9^{\circ}$ ano \\
\hline
\end{tabular}

Quadro 3: Nomenclatura comum às muitas possibilidades de organização do ensino Fonte: Brasil (2004a).

A idade cronológica não foi essencialmente o aspecto definidor da entrada da criança de seis anos no ensino fundamental, como ressalta o documento em análise. Foram definidas algumas características das crianças de seis anos que as diferenciam das de outras faixas etárias, especialmente no que tange a aspectos como imaginação, curiosidade, movimento, desejo de aprender e conhecer o mundo por meio do brincar. Vejamos:

Nessa faixa etária a criança já apresenta grandes possibilidades de simbolizar e compreender o mundo, estruturando seu pensamento e fazendo uso de múltiplas linguagens. Esse desenvolvimento possibilita a elas participar de jogos que envolvem regras e se apropriar de conhecimentos, valores e práticas sociais construídos na cultura. Nessa fase, vivem um momento crucial de suas vidas no que se refere à construção de sua autonomia e de sua identidade (BRASIL, 2004a, p. 19).

Nesse sentido, defende que a entrada da criança na escola não pode assinalar uma ruptura com o processo de aprendizagem já desencadeado, vivido em casa ou na instituição de educação infantil; pelo contrário, deve dar continuidade às experiências anteriores, de modo que, gradativamente, a criança sistematize conhecimentos, destacando os referentes à escrita. Afirma que a aprendizagem de tal linguagem deve ocorrer de forma contextualizada, fazendo uso desse sistema simbólico em situações de aprendizagem. Por isso, o referido documento defende "[...] que a transição da Educação infantil para o Ensino Fundamental ocorra da forma mais natural possível, não provocando nas crianças rupturas e impactos negativos" (BRASIL, 2004a, p. 22). Sugere a necessidade de

[...] possibilitar o acesso aos diversos usos da leitura e da escrita não é suficiente para que elas se alfabetizem. É necessário, além disso, um trabalho sistemático, centrado tanto nos aspectos funcionais e textuais, quanto no aprendizado dos aspectos gráficos da linguagem escrita e daqueles referentes ao sistema alfabético de representação (BRASIL, 2004a, p. 21).

Para isso, devem ser propiciados momentos de formação ao professor do aluno de seis anos, pois o trabalho docente exige continuidade na formação dos sujeitos sociais historicamente envolvidos com a ação pedagógica no desenvolvimento de atitudes investigativas, pedagógicas e metodológicas, como expõe o documento.

O segundo relatório, intitulado "Ensino Fundamental de Nove Anos: $2^{\circ}$ Relatório" (BRASIL, 2005), traz as principais ações realizadas pela SEB/DPE/COEF, em parceria com as secretarias estaduais e municipais de educação, de agosto de 2004 a julho de 2005. Uma dessas ações foi a realização do "Encontro Nacional: Ensino Fundamental de Nove Anos", ocorrido nos dias 18 e 19 de novembro de 2004, em Brasília. Esse evento recebeu, além dos representantes dessas secretarias, convidados especialistas na temática. Vale destacar que a programação desenvolvida propunha-se debater:

[...] políticas públicas da educação básica, política de financiamento para a educação básica, equidade e qualidade social da educação, o direito a 
infância na escola, infância e múltiplas linguagens, tempo e espaço do Ensino Fundamental, elaboração e desenvolvimento de programas e projetos educacionais (BRASIL, 2005, p. 2).

De acordo com esse relatório, a realização desse evento nacional foi fundamental para ampliar a discussão a respeito do ensino fundamental de nove anos, bem como levantar informações sobre o seu desenvolvimento nos estados e municípios que dele participaram. Para explicitar a importância da contribuição do referido encontro, o relatório apresenta quadros com entidades participantes, instituições promotoras, especialistas convidados, secretarias de educação municipais e estaduais envolvidas. Também destaca os municípios que já aderiram a implantação do programa. Ao final do relatório, há um levantamento do número de matrículas no ensino fundamental de nove anos, considerando as dependências administrativas federal, estadual, municipal e privada. O relatório é encerrado com perguntas elaboradas pelos participantes do evento (sem as respectivas respostas) referentes a nomenclatura, idade necessária para ingresso, relação com a educação infantil, conteúdos a serem ministrados no primeiro ano, avaliação, recursos financeiros, diretrizes pedagógicas, implicações administrativas, implicações pedagógicas, entre outros. As muitas questões levantadas indicam, conforme declara o documento ora apresentado, que "se está diante de um programa desafiador" (BRASIL, 2005, p. 6).

Ao publicar o terceiro relatório, intitulado "Ampliação do Ensino Fundamental para nove anos: $3^{\circ}$ relatório do programa", o objetivo do referido órgão era, "[...] além de atualizar as informações sobre o programa, responder a dúvidas e a questionamentos dos sistemas de ensino sobre a ampliação do Ensino Fundamental para nove anos" (BRASIL, 2006, p. 4). Assim, o MEC acreditava estar cumprindo seu papel de assegurar que esse processo de transição do ensino obrigatório de oito para nove anos de duração não se tornasse apenas uma mudança de cunho administrativo.

O Ministério da Educação (MEC), buscando fortalecer o debate sobre a infância na Educação Básica, especialmente com relação à ampliação do Ensino Fundamental para nove anos, envida esforços no sentido de buscar assegurar que o cumprimento da Lei $\mathrm{n}^{\circ} 11.274$, de 6 de fevereiro de 2006, que institui o Ensino Fundamental de nove anos de duração com a inclusão das crianças de 6 anos de idade, não se configure medida meramente administrativa (BRASIL, 2006, p. 4).

Com essa pretensão, o MEC, em parceria com as Secretarias de Educação (municipais e estaduais), juntamente com a Undime e o Conselho Nacional dos Secretários de Educação (Consed), realizou, no decorrer do ano de 2005, dez encontros regionais nos municípios de: Cuiabá, MT; São Luiz, MA; Maceió, AL; Natal, RN; Belém, PA; Rio Branco, AC; Belo Horizonte, BH; Curitiba, PR; Guarulhos, SP e Porto Alegre-RS (BRASIL, 2006).

Ao longo desses encontros o referido órgão recebeu perguntas de gestores e demais profissionais da educação sobre a implementação do ensino fundamental com nove anos de duração. Essas questões foram classificadas, agrupadas e analisadas por assunto/tema. A seguir, destacamos algumas orientações oriundas dessas questões e suas respectivas respostas acerca: das faixas etárias previstas; das nomenclaturas de cada nível de ensino; do prazo de implantação do ensino fundamental de nove anos; da necessidade de reorganizar as instituições e o ensino; da ruptura entre os anos iniciais e finais do ensino fundamental.

Para tratar da idade para o ingresso no ensino fundamental com de nove anos de duração, o terceiro relatório recorre a Resolução CNE/CEB n ${ }^{\circ}$ 3, de 03 de agosto de 2005, em seu art. $1^{\circ}$, que estabelece: "[...] a antecipação da obrigatoriedade de matrícula no Ensino 
Fundamental aos seis anos de idade implica a ampliação da duração do Ensino Fundamental para nove anos". Com base no art. $2^{\circ}$ da resolução mencionada, aponta que o ensino fundamental de nove anos de duração e a educação infantil deverão adotar a seguinte nomenclatura e correspondente faixa etária:

\begin{tabular}{|c|c|c|}
\hline Etapa de ensino & Faixa etária prevista & Duração \\
\hline Educação infantil & $\begin{array}{c}\text { até } \mathbf{5} \text { anos de idade } \\
\text { até } 3 \text { anos de idade }\end{array}$ \\
Creche & 4 e 5 anos de idade & \\
Pré-Escola & Até 14 anos & $\mathbf{9}$ anos \\
Ensino Fundamental & De 6 a 10 anos & 5 anos \\
Anos Iniciais & De 11 a 14 anos & 4 anos \\
Anos Finais &
\end{tabular}

Quadro 5: Nomenclatura específica para a organização da educação infantil e do ensino fundamental de nove anos

Fonte: Brasil (2006).

O Parecer CNE/CEB n. ${ }^{\circ}$ 6/2005, aprovado em 08 de junho de 2005, citado pelo terceiro relatório, determina que os "[...] sistemas de ensino deverão fixar as condições para a matrícula de crianças de seis anos no Ensino Fundamental quanto à idade cronológica: que tenham seis anos completos ou que venham a completar seis anos no início do ano letivo" (BRASIL, 2006). Para a ampliação do ensino fundamental de nove anos, haverá o acréscimo de um ano no início dessa modalidade de ensino. Por fim, abordando a nomenclatura, de acordo com a mencionada Resolução, o ensino fundamental se organiza em: anos iniciais (do $1^{\circ}$ ao $5^{\circ}$ ano), e anos finais (do $6^{\circ}$ ao $9^{\circ}$ ano).

Ainda no documento acima referido é possível encontrar orientações quanto ao prazo para implementação do ensino fundamental de nove anos. De acordo com a Lei n. ${ }^{\circ}$ 11.274, de 6 de fevereiro de 2006, art. 5, "Os Municípios, os Estados e o Distrito Federal terão prazo até 2010 para implementar a obrigatoriedade para o Ensino Fundamental" (BRASIL, 2006, p. 7). Esta lei estabelece ainda que as escolas privadas também teriam o mesmo prazo para cumprir tal determinação.

Assim como os demais, o terceiro relatório também traz orientações quanto à organização do ensino e aponta algumas ações que precisariam ser implementadas, tendo em vista a ampliação do ensino fundamental. São elas:

- Reorganizar o Ensino Fundamental tendo em vista não apenas o primeiro ano, mas toda a estrutura dos nove anos de ensino;

- Planejar oferta de vagas, número de salas de aula, adequação dos espaços físicos, número de professores e profissionais de apoio, adequação de material pedagógico;

- Realizar chamada pública, conforme estabelece a LDB;

- Providenciar a normalização legal no Conselho de Educação (BRASIL, 2006, p. 7).

Outra inquietação apontada neste último relatório reside no fato de que, em geral, há uma ruptura entre os anos iniciais e os anos finais desse nível de ensino, decorrente da fragmentação entre conhecimento, aprendizagem e trabalho pedagógico. Assim, orienta que as normalizações dos respectivos Conselhos de Educação apontem para a necessidade de criar instrumentos para que as crianças não sofram prejuízos em sua trajetória escolar.

"Ensino Fundamental de Nove Anos: passo a passo do processo de implantação" é outro documento de caráter legal, organizado e divulgado pelo MEC, em 2009, tendo como 
finalidade prestar auxílio aos gestores municipais e estaduais, aos conselhos de educação, a comunidade escolar e demais órgãos e instituições. Tal como os outros documentos anteriormente analisados, este também traz os objetivos para a ampliação do ensino fundamental para nove anos de duração, citando que, para isso, é necessário:

- Melhorar as condições de equidade e de qualidade da Educação Básica;

- Estruturar um novo Ensino Fundamental para que as crianças prossigam nos estudos, alcançando maior nível de escolaridade;

- Assegurar que, ingressando mais cedo no sistema de ensino, as crianças tenham um tempo mais longo para as aprendizagens da alfabetização e do letramento (BRASIL, 2009, p. 5).

O ensino fundamental estendido para nove anos de duração passou a ser um novo ensino fundamental. Isso exige uma proposta pedagógica própria para ser desenvolvida em cada escola, prevê o documento. Assim, um novo ensino fundamental exige novo currículo, que deve compreender:

a) os objetivos a serem alcançados por meio do processo de ensino [...];

b) as áreas do conhecimento [...];

c) matriz curricular definida pelos sistemas de ensino [...];

d) oferta equitativa de aprendizagens e consequente distribuição equitativa da carga horária entre os componentes curriculares [...];

e) as diversas expressões da criança [...];

f) os conteúdos a serem ensinados e aprendidos [...];

g) as experiências de aprendizagem escolares a serem vividas pelos alunos;

h) os processos de avaliação que terminam por influir nos conteúdos e nos procedimentos selecionados nos diferentes graus da escolarização (BRASIL, 2009, p. 14).

Para ajudar as escolas na compreensão das orientações teórico-metodológicas tendo em vista a necessária reformulação curricular, o referido documento apresenta uma tabela que contempla a correspondência da organização do ensino fundamental em oito e nove anos, tendo em vista o processo de transição de uma forma de organização curricular para a outra:

\begin{tabular}{|c|c|c|}
\hline $\begin{array}{c}\text { Oito anos de } \\
\text { duração }\end{array}$ & $\begin{array}{c}\text { Nove anos de } \\
\text { duração }\end{array}$ & $\begin{array}{c}\text { Idade correspondente ao } \\
\text { início do ano letivo } \\
\text { (sem distorção idade/ano) }\end{array}$ \\
\hline- & $1^{\mathbf{o}}$ ano & 6 anos \\
\hline $1^{\mathbf{a}}$ série & $2^{\mathbf{o}}$ ano & 7 anos \\
\hline $2^{\mathbf{a}}$ série & $3^{\mathbf{o}}$ ano & 8 anos \\
\hline $3^{\mathrm{a}}$ série & $4^{\mathbf{o}}$ ano & 9 anos \\
\hline $4^{\mathrm{a}}$ série & $5^{\mathbf{o}}$ ano & 10 anos \\
\hline $5^{\mathrm{a}}$ série & $6^{\mathbf{o}}$ ano & 11 anos \\
\hline $6^{\text {a }}$ série & $7^{\mathbf{o}}$ ano & 12 anos \\
\hline $7^{\mathrm{a}}$ série & $8^{\mathbf{o}}$ ano & 13 anos \\
\hline $8^{\text {a }}$ série & $9^{\mathbf{o}}$ ano & 14 anos \\
\hline
\end{tabular}

Quadro 7: Equivalência da organização do Ensino Fundamental em oito e nove anos Fonte: Brasil (2009). 
O documento lembra que, devido a complexidade dos processos de alfabetização e letramento no início do processo de escolarização, “[...] a maioria das crianças necessita de mais de duzentos dias letivos para consolidar essas aprendizagens em conjunto com outras áreas do conhecimento estabelecidas nas Diretrizes Curriculares Nacionais para o Ensino Fundamental" (BRASIL, 2009, p. 17). Determina, então, que os três anos iniciais do ensino fundamental sejam destinados à alfabetização e ao letramento e que a complexidade de tais processos precisa ser considerada ao avaliar os alunos. Assim,

[...] recorrendo ao Parecer CNE/CEB no 4/2008, esse reafirma que o processo de avaliação deve considerar, de forma prioritária, que os três anos iniciais constituam-se em um período destinado à construção de conhecimentos que solidifiquem o processo de alfabetização e de letramento. Portanto os procedimentos de avaliação devem acompanhar a necessidade de se trabalhar pedagogicamente nesses 3 anos para o desenvolvimento das diversas formas de expressão das crianças (BRASIL, 2009, p. 17).

Defende a necessidade de planejar e avaliar o que será ensinado e o que as crianças aprenderão desde o início da escolarização. "É preciso não perder tempo, não deixar para os anos seguintes o que devemos assegurar desde a entrada da criança, aos seis anos, na escola" (BRASIL, 2009a). Objetivando verificar se o direito ao aprendizado está garantido para cada aluno, o referido documento destaca duas avaliações externas realizadas pelo MEC em nível nacional. São elas a Prova Brasil e a Provinha Brasil. Assim o documento define tais instrumentos avaliativos:

Prova Brasil: é o instrumento de medida das competências leitora e matemática, aplicado em praticamente todas as crianças e jovens matriculados na quarta e oitava séries (quinto e nono anos). Provinha Brasil: é o instrumento elaborado para oferecer aos professores e aos gestores das escolas públicas e das redes de ensino um diagnóstico do nível de alfabetização dos alunos, ainda no início do processo de aprendizagem, permitindo assim intervenções com vista à correção de possíveis insuficiências apresentadas nas áreas de leitura e escrita. Essa avaliação é um instrumento pedagógico sem finalidades classificatórias (BRASIL, 2009 , p. 17, grifos nossos).

Ainda no tocante à avaliação, o documento ressalta um dos critérios estabelecidos no art. 24, inciso V, alínea "a" da Lei $\mathrm{n}^{\circ}$ 9.394/96, o qual estabelece que a avaliação deva verificar, de forma contínua e cumulativa, o desempenho do aluno, "[...] com prevalência dos aspectos qualitativos e dos resultados ao longo do período sobre os de eventuais provas finais" (BRASIL, 2009, p. 16).

Outra questão sobre a avaliação apontada pelo documento é a necessidade de serem observados os princípios essenciais da avaliação elaborados pelo Conselho Nacional de Educação (PARECER CNE/CEB nº 4/2008):

- processual, participativa, formativa, cumulativa e diagnóstica e, portanto, redimensionadora da ação pedagógica;

- não pode repetir a prática tradicional limitada a avaliar apenas os resultados finais traduzidos em notas ou conceitos;

- não pode ser adotada como mera verificação de conhecimentos visando ao caráter classificatório; 
- é indispensável a elaboração de instrumentos e procedimentos de observação, de acompanhamento contínuo, de registro e de reflexão permanente sobre o processo de ensino e de aprendizagem;

- a avaliação, como um momento necessário à construção de conhecimentos pelas crianças no processo de alfabetização (BRASIL, 2009a, p. 16).

O documento também faz menção à formação, às condições de trabalho e à carreira dos profissionais da educação, lembrando o estabelecido no artigo 67 da LDB no 9.394/96, segundo o qual os sistemas de ensino devem promover a valorização desses profissionais da educação e assegurar os planos de carreira, conferindo:

I - ingresso exclusivamente por concurso público de provas e títulos;

II - aperfeiçoamento profissional continuado, inclusive com licenciamento periódico remunerado para esse fim;

III - piso salarial profissional;

IV - progressão funcional baseada na titulação ou habilitação, e na avaliação do desempenho;

V - período reservado a estudos, planejamentos e avaliação, incluído na carga de trabalho;

VI - condições adequadas de trabalho (BRASIL, 1996, p. 22).

Ao final do documento, encontram-se também perguntas e respostas mais frequentes coletadas mediante consultas feitas ao MEC. Por serem muitas, para facilitar a visualização pelo leitor, as organizamos em um quadro, destacando os temas/assuntos e a quantidade de questões referentes:

\begin{tabular}{|l|c|}
\hline \multicolumn{1}{|c|}{ Temas/assuntos } & $\begin{array}{c}\text { Quantidade } \\
\text { de questões }\end{array}$ \\
\hline Matrícula e formação de turmas & 14 \\
\hline Implementação & 7 \\
\hline Currículo & 6 \\
\hline Data de corte & 4 \\
\hline Classes multisseriadas e defasagem idade/série & 3 \\
\hline Formação de professores & 2 \\
\hline Nomenclatura & 2 \\
\hline Infraestrutura & 1 \\
\hline Documentação escolar & 1 \\
\hline Livro didático & 1 \\
\hline TOTAL & $\mathbf{4 1}$ \\
\hline
\end{tabular}

Quadro 4: Perguntas e respostas mais frequentes

Fonte: Vendrame (2014).

As temáticas das questões apresentadas revelam que os documentos orientadores elaborados pelo MEC até aquele momento ainda não tinham sido suficientes para sanar as dúvidas e preocupações das equipes pedagógicas quanto à organização mínima para início das atividades, o que possivelmente poderia comprometer a implantação do ensino fundamental de nove anos e a qualidade do ensino oferecido. 


\section{Algumas considerações finais}

Neste artigo evidenciamos as muitas ações do MEC em prol da divulgação e implantação do ensino fundamental, que passou de oito para nove anos de duração. Destacamos que o referido órgão preocupou-se em orientar sua implementação, não havendo negligência neste aspecto.

Contudo, compreendermos que para a organização do novo ensino fundamental com nove anos de duração e, consequentemente, de uma proposta pedagógica, implica a necessidade imprescindível de um debate aprofundado sobre essa proposta, abrangendo a formação de professores, as condições de infraestrutura, os recursos didático-pedagógicos adequados ao atendimento e a organização dos tempos e espaços escolares.

Assim, apesar de todos esses documentos terem sido amplamente divulgados, enviados às escolas e disponibilizados no portal do MEC ao público interessado, tais esforços não garantiram que essa ampliação do ensino fundamental para nove anos fosse exitosa em termos de organização do ensino, ampliando a qualidade da educação brasileira.

Neste sentido, é preciso que as políticas públicas educacionais sejam extremamente pensadas e elaboradas, considerando suas dimensões econômica (financiamento, custo), de gestão (de sistemas, redes e instituições educacionais) e pedagógica (currículo, avaliação, material didático e formação de professores), para que realmente se obtenha êxito nas ações e se consiga mudanças no processo de aprendizagem das crianças e no sistema educativo como um todo.

\section{Referências}

BRASIL. Ministério da Educação e Cultura. Lei n⿳0. 4.024, de 20 de dezembro de 1961. Brasília, DF: Diário Oficial da União; MEC, 1961.

. Ministério da Educação e Cultura. Lei no. 5.692, de 11 de agosto de 1971.

Brasília, DF: Diário Oficial da União; MEC, 1971.

. Ministério da Educação e Cultura. Lei no. 9.394, de 20 de dezembro de 1996. Brasília, DF: Diário Oficial da União; MEC, 1996.

.Lei $\mathrm{n}^{\circ}$ 10.172, de 9 de janeiro de 2001 - Aprova o Plano Nacional de Educação e dá outras providências. Brasília: Presidência da República, 2001.

Lei n. 11.114 , de 16 de maio de 2005. Altera os artigos. $6^{\circ}, 30,32$, e 87 da Lei ${ }^{\circ}$ 9.394 de 20 de dezembro de 2006, com o objetivo de tornar obrigatório o início do ensino fundamental de seis anos de idade. Diário Oficial da União, Brasília, 2005.

Lei n.11.274, de 06 de fevereiro de 2006. Altera a redação dos artigos. 29, 30, 32 e 87 da Lei ${ }^{\circ} 9.394$ de 20 de dezembro de 1996, que estabelece as diretrizes e bases da educação nacional, dispondo sobre a educação de nove anos para o ensino fundamental, 1508 com matrícula obrigatória a partir dos 6 (seis) anos de idade. Diário Oficial da União, Brasília, 2006. 
Lei $\mathrm{n}^{\circ} .10 .061$, de 27 de outubro de 2009. Altera o inciso II do art. $4^{\circ}$ e o inciso VI do art. 10 da Lei ${ }^{\circ}$ 9.394, de 20 de dezembro de 1996, para assegurar o acesso de todos os interessados ao ensino médio público. Diário Oficial da União, Brasília, 2009.

. Emenda Constitucional nº 59, de 11 de novembro de 2009.

. Ministério da Educação e Cultura. Ensino Fundamental de nove anos: orientações gerais. Brasília, DF: MEC/SEB, 2004a.

. Ministério da Educação e Cultura. Ensino Fundamental de Nove Anos - $1^{\circ}$ Relatório. Brasília, DF: MEC/SEB, $2004 b$.

. Ministério da Educação e Cultura. Ensino Fundamental de Nove Anos - $2^{\circ}$ Relatório. Brasília, DF: MEC/SEB, 2005.

. Ministério da Educação e Cultura. Ampliação do Ensino Fundamental para nove anos: $3^{\circ}$ relatório do programa. Brasília, DF: MEC/SEB, 2006.

. Ministério da Educação e Cultura. Ensino Fundamental de nove anos: passo a passo do processo de implantação. 2 ed. Brasília, DF: MEC/SEB, 2009.

. Ministério da Educação. Secretaria de Educação Básica. Diretrizes Curriculares Nacionais para a Educação Infantil. Brasília, DF: MEC, SEB, 2010.

CZYZEWSKI, A. A organização dos espaços educativos no processo de ampliação do ensino fundamental. 2012. 56 f. Monografia (Trabalho de Conclusão de Curso, Graduação em Pedagogia) - Universidade Estadual de Maringá, Maringá, 2012.

FURGHESTTI, M. L. S.; GRECO, M. T. C.; CARDOSO, R. C. F. Ensino fundamental de nove anos: os impactos das políticas para a alfabetização com letramento. In: IX Seminário de Pesquisa em Educação da Região Sul (ANPEDSUL), 2012, Caxias do Sul. Anais do... Caxias do Sul, 2012, p. 1-18.

SCHNEIDER, P. M. DURLI, Z. Ensino fundamental de nove anos: aspectos legais e didático-pedagógicos. Joaçaba, n. 2, v. 34, p. 189-214, jul/dez. 2009.

VENDRAME, C.B. Organização do ensino para a apropriação da linguagem escrita: a Teoria Histórico-Cultural nos documentos oficiais orientadores do ensino fundamental de nove anos. 2015. 132 f. Dissertação (Educação) - Universidade Estadual de Maringá, Paraná, 2015.

\footnotetext{
${ }^{1}$ Vale destacar que existe um movimento organizado pelo Fórum de Educação infantil do Paraná (FEIPAR) que discute a Lei Estadual $\mathrm{n}^{\circ} 16.049 / 09$,o qual determina o corte etário para ingresso no $1^{\circ}$ ano do ensino fundamental de crianças que completam seis anos de idade até 31 de dezembro do ano em que ocorrer a matrícula.
}

Recebido: $\quad$ março-15 Aprovado: abril-15 